\title{
Assessment of Some Basic Empirical Path Loss Model for Vhf and Uhf in Kano City Nigerian Environment
}

\author{
Mr. Saheed Tunde Zubair \\ Faculty of Computer Science, School of Computer Science \& Information Technology, \\ Skyline University Nigeria, Nigeria, \\ Email: saheedtzubair@gmail.com \\ Dr. Vijay Arputharaj \\ HOD - Computer Science, School of Computer Science \& Information Technology, \\ Skyline University Nigeria, Nigeria, \\ Email:phdvij@gmail.com \\ Dr. Ashok Kumar \\ Faculty of Computer Science, School of Computer Science \& Information Technology, \\ Skyline University Nigeria, Nigeria, \\ Email: williamashok@gmail.com \\ Ms.Pushpa Rega Ganesan \\ Lecturer, Department of Software Engineering, Institute of Technology, \\ Jigjiga University, Ethiopia \\ Email: pushparega994@gmail.com
}

\begin{abstract}
High demands of wireless data service are increase globally and this makes Empirical path loss models of great interest. Path loss Propagation models are useful as predictive tools for receiving signal intensity at any particular distance between the transmitter and the receiver at that particular point, it is important in many ways, such as Base Transceiver Stations (BTS) location, radio coverage area estimation, frequency assignments, interference analysis, optimization transfer, power adjustment and connection budget. This paper presents an assessments and evaluation of five widely used empirical path loss models in predicting signal in the VHF and UHF bands in Kano City, Nigeria. In the work, five error analysis methods are used and a large scale field strength measurement was conducted within Kano State metropolis using specially configured dual band handset, GPS and GENEX® Probe software, data samples were collected along a predefined route Measurement of the drive test was carried out in Kano, Nigeria to obtain path loss data from various base station transmitters at varying distances. The routes covered are Zaria highway through eastern bypass road Dan Agundi to Bayero University, Kano old site, Hotoro GRA, Badawa Layout to SabonGari along MM way and Kabuga to Bayero University New site.It was found that HATA model provides the best results in terms of minimum mean Error, RMSE and SCRMSE. HATA model has the best fit which falls within the acceptable range of $\pm 10 \mathrm{~dB}$.
\end{abstract}

Keywords - Wireless data, path loss, VHF Bands, UHF Bands, Kano City

Date of Submission: Aug 30, 2021

Date of Acceptance: Oct 21, 2021

\section{INTRODUCTION}

The demand for wireless connectivity has sky rocketed in the last decade and even more so in the last few years. The demand of fast connections which can support all of the wireless needs is required. From home network, to network in the working place and the coffee shop down the street are expected to be connected. And this has reached a point where performance can only be accomplished by allowing efficient use of spectrum.[1], But unfortunately this wireless connection experience reduction in power spectral density (attenuation) of an electromagnetic wave, as it propagates through the medium in which it is travelling, thereby weakening the signal strength and this effect is recognized as path loss [2].

Path loss models are central in the design of wireless communications systems such as mobile telephone, radio coverage prediction, interference analysis, television broadcasting systems link public protection budgets with emergency services. Public safety systems also use the lower part of the VHF (Very High Frequency) band, and the coverage areas of these systems may exceed hundreds of square kilometers.

UHF (Ultra High Frequency) band is commonly used for terrestrial television broadcasting, mobile cellular networks, Wi-Fi, satellite communications and in many other applications. The coverage area of these networks varies from less than one square kilometer for cellular television 
broadcasting to hundreds of square kilometers. It is clear that path loss prediction particularly in urban areas is a complex problem as it requires previous information of the transmitter's operating frequency, the degree of urbanization (clutter cover) and the complexity of the terrain. [1]

The communication path linking the transmitter and the receiver can vary from a direct, pure line of sight to that obstructed by obstacles such as houses, mountains and leaves. Path loss is a key element in the study of the budget relation and the design of telecommunications systems[3] (Anderson et al., 2008.). Propagation Models for transmission with low cost and easy device design alternatives have been established as Site estimates are costly. Channel modeling is required to forecast route loss in cellular network base station development since it tells design engineers how much power a transmitter needs to emit to service a given cell location.

A typical network comprises of a transmitter, a receiver and a natural environment, a model that can be used for a specific frequency band to predict the behavior of a radio signal in a specific environment.

The effectiveness of the communication system is determined by the design parameters, the values of which the system designer may choose, and the physical requirements over which the designer has influence [4]

It has been observed that wireless connections experience a decrease in the spectral power density (attenuation) of the electromagnetic wave. As it spreads through the environments in which it travels, it weakens the signal strength and receives low or no signal strength in order to establish a connection at all,

Due to the fact that most cellular network operators employ basic widely used propagation models for predicting signal losses when planning wireless systems in a given environment. However, it is unclear whether of the commonly used models provides a better match. Most of the models used today were developed based on measurements taken in locations other than Nigeria, and therefore their appropriateness in terms of utilization may be called into question owing to environmental differences. Furthermore, the idiosyncrasies of these models result in large prediction errors when deployed in a context other than the one for which they were originally designed

As a result, error analysis is required to evaluate the amount of variation from the defined model and its actual execution outside of the regions for which it was designed. As a result, precise assessment of propagation models in the GSM and WCMDA bands is required in order to change a model or pick a model that provides better fits in order to achieve high accuracy in the planning, design, and even implementation stages. This study evaluates and assesses the commonly used fundamental empirical route loss models for signal prediction in the VHF and UHF bands in Kano, Nigeria.

\section{METHODOLOGY}

Data collection began at the feet of the Cell Tower (BTS), and the vehicle traveled outward from the BTS in the direction of the primary lobes of each transmitting antenna.

The Measurements were carried out in Kano State, Nigeria with coordinates $\left(11{ }^{\circ} 30^{\prime} \mathrm{N} \quad 8 \quad{ }^{\circ}\right.$ $\left.30^{\prime} \mathrm{E} \quad 11.5{ }^{\circ} \mathrm{N} \quad 8.5{ }^{\circ} \mathrm{E}\right)$. The state of Kano is located in the north west of the country with an average building height of $15 \mathrm{~m}$. Its metropolitan population and is Nigeria's second largest city after Lagos. The Kano urban area covers $137 \mathrm{~km} 2$ with a population of 2,163,225 inhabitants as in the 2006 Nigerian census. The Metropolitan Area is 499 sq.km. /map/ng/Nigeria/regions/kano-state).

In the city all tests were performed. Hotoro-NNDC Quarters, Hotoro-Kaduna-Zaria Highway along the East Bypass Road and Airport Road-Kofar Ruwa Road, Dan Agundi-Kabuga, Rijiyar Zaki-Bayero University, Kano (BUK) (Gwarzo Road), and others were among the paths covered by Kano City.

Using a specially designed handset and GPS, both coupled to a laptop placed in a vehicle socket, are linked to an inverter. The phone is designed to automatically make calls while driving. The call lasts for the same duration (in our case 30s hold duration) and then the call drops, the phone remains idle for a period of time, then another call was made.

Throughout the drive test the phone records all the signalling and message data it receives and transmits. Together with location information provided by a GPS, this information is transferred to the laptop and subsequently placed into a database (external hard drive) for where drive test analysis software known as GENEX SHARE was used to analyse the recorded signals.

Significant information is given in the GENEX PROBE software, such as the Basic Station ID code (BSIC), Signal Strength Level (dB), Length, Latitude, etc. Altitude, and Frequency of the BTS, and Distance from the MS to the BTS of the service cell. etc. Figure 3.2 shows the complete set up of spectrum analyser and laptops all in a moving car to collect data. 


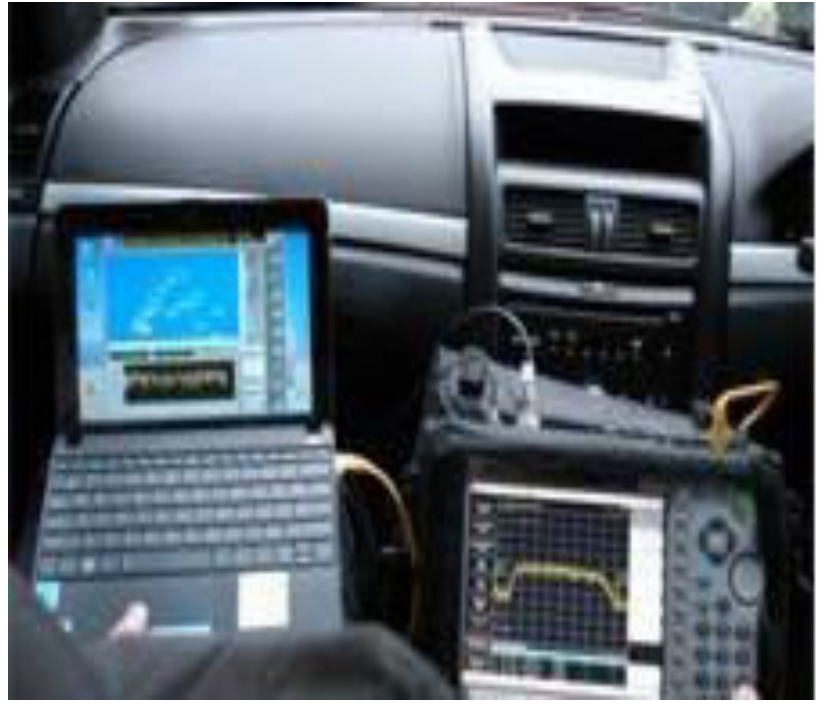

Fig 3.2 data collection in progress while driving at $40 \mathrm{~km} / \mathrm{hr}$. along the routes

When replaying the $\log$ file of the drive test data stored in an external drive on the software, the Altitude (m), Distance (Km), Received Signal Strength Level (dB), longitude, latitude, elevation and clutter height where recorded as the distance changed. In a text file format (.txt) one after the other Log files obtained by the data gathering process were inserted.

The data in this text format has been sorted in Microsoft Excel appropriately and then entered into MATLAB SOFTWARE to achieve the results. The equation of the often used empirical models has been included. With fieldmeasured data, Hata, COST 231 models, Ikegami, Egli and Ilorin were assessed.

The provision of the Digital Terrain Chart, clutter class information and a vector map displaying all the main roadways with the mean height of each storm improves forecast precision [5] (Greenberg and Greenberg, 2011).

Figure 3.3 shows the active serving and neighbouring cell, GPS information and scanner which scanned other network signal strength along the route.

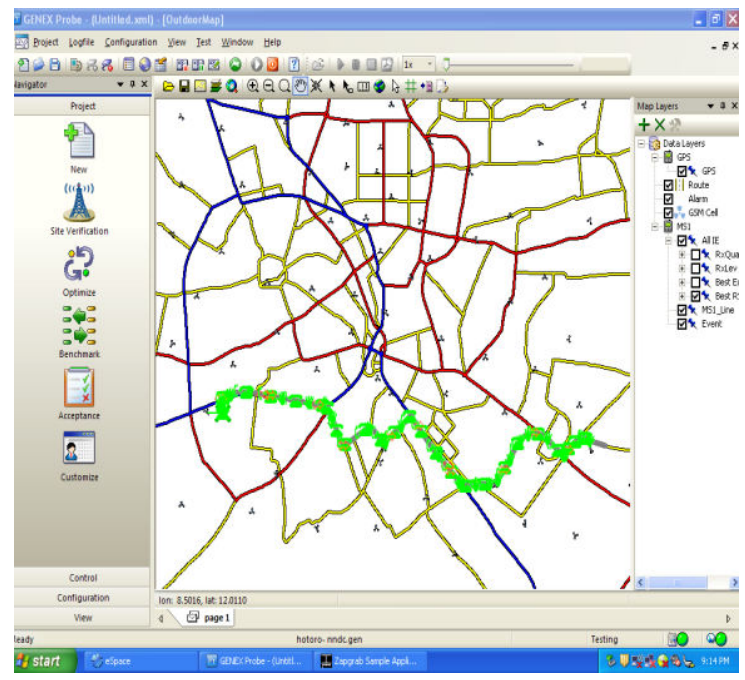

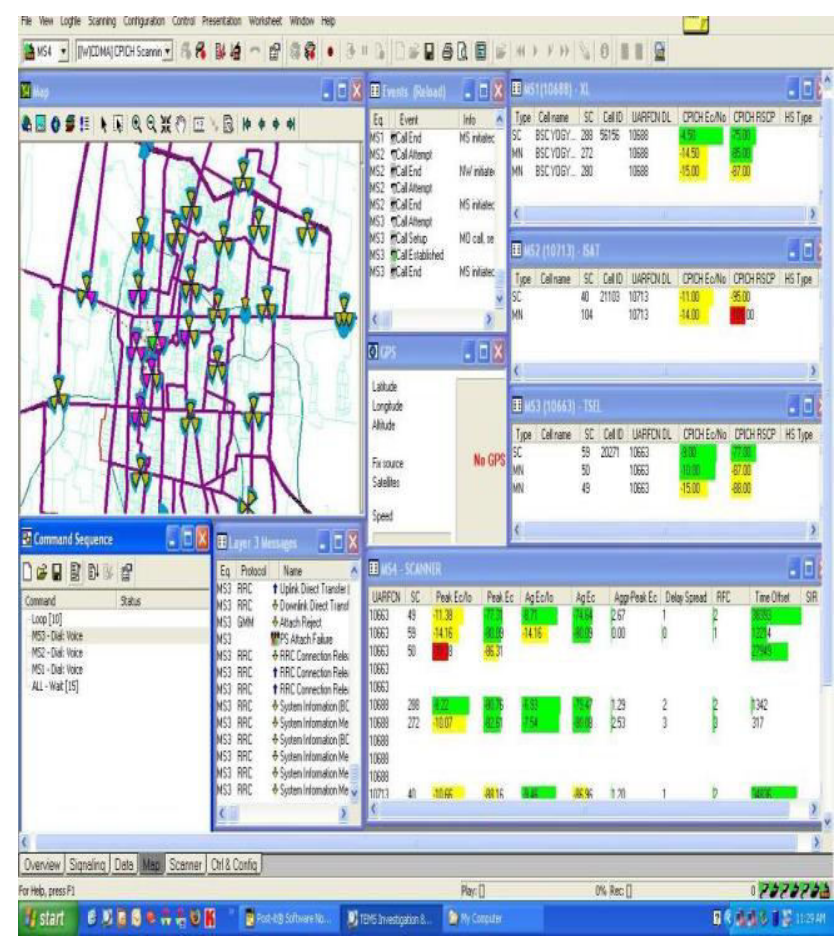

\section{III.MEASUREMENT EQUIPMENTS AND CONFIGURATION}

During the estimation of respective path losses at different distances the following site and instrument data were used

\section{TABLE $3.1 \quad$ SIMULATION PARAMETERS PARAMETER}

VALUE

Agilent Spectrum Analyzer Agilent N9342C

$100 \mathrm{~Hz}-7 \mathrm{GHz}$

BTS transmitting power of $40 \mathrm{~W}$

Preamplifier $20 \mathrm{~dB}$

Resolution bandwidth (RBW) $10 \mathrm{kHz}$

BTS Antenna Height (ht) 30m

Mobile antenna height (ht) $1.5 \mathrm{~m}$

GPS, Dual band hand set and inverter

Hp laptop

8Gb Ram and 1 terabyte Hard disk

Coordinates

$11^{\circ} 30^{\prime} \mathrm{N} \quad 8^{\circ} 30^{\prime} \mathrm{E} 11.5^{\circ} \mathrm{N} \quad 8.5^{\circ} \mathrm{E}$ 


\section{RESULT AND DISCUSSION}

This presents the results and explanations of the simulation on the performance of the propagation models when estimating the measured and predicted data obtained by the signal level. Figures 4.1 to 4.9 demonstrate how the propagation models behaved when estimating the measured and predicted data received by the signal level. Each of the propagation models has a similar pattern for all routes and investigated transmitter.

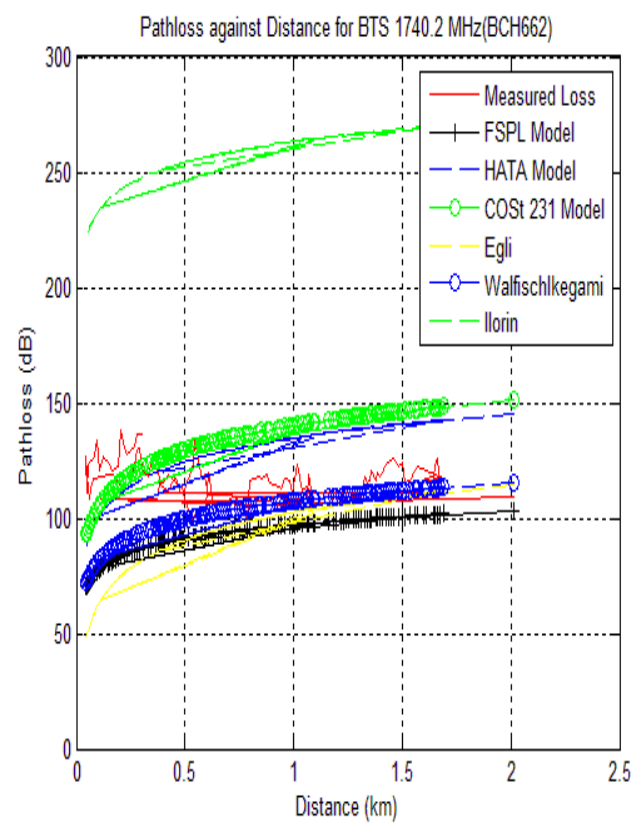

Fig 4.1. Comparison of empirical models with measured path loss along Airport road

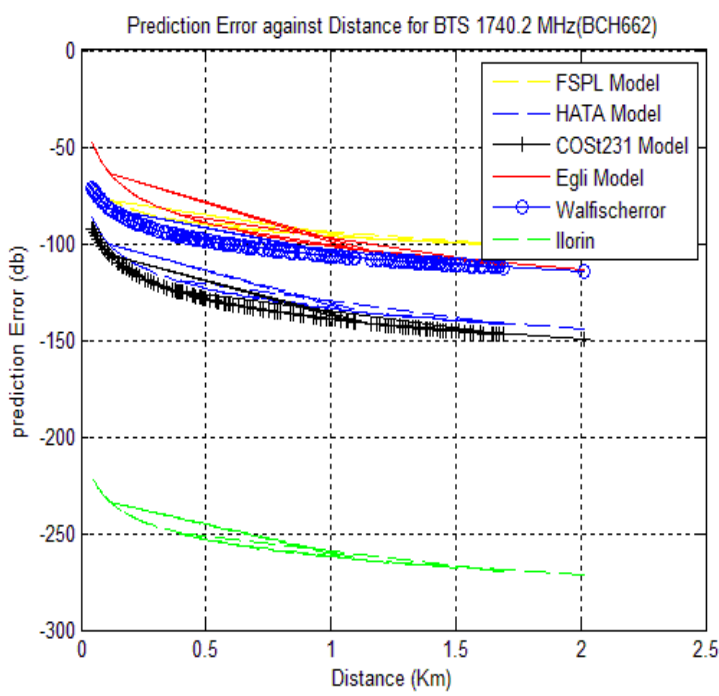

Figure 4.2 predictions Error against distance for the Basic empirical models along the Airport road,

The relation of the observed path loss with the expected path Loss as a function of distance for $\mathrm{BCH} 662$ is shown in figure 4.1 above. Within the first few kilometres along the road, the HATA and the COST231 models are in lined with the calculated path loss, then later on they over estimate the path loss. The FSPL and Egli models underestimate the loss of path across the field of interest. Although Walfisch Ikegami, the model provides better performance. The Walfisch Ikegami model offers the lowest RMSE value of $12 \mathrm{~dB}$ for the overall route which is a better result compared to other models

However, ILORIN, Egli and FSPL work badly with higher RMSE and STDV values.

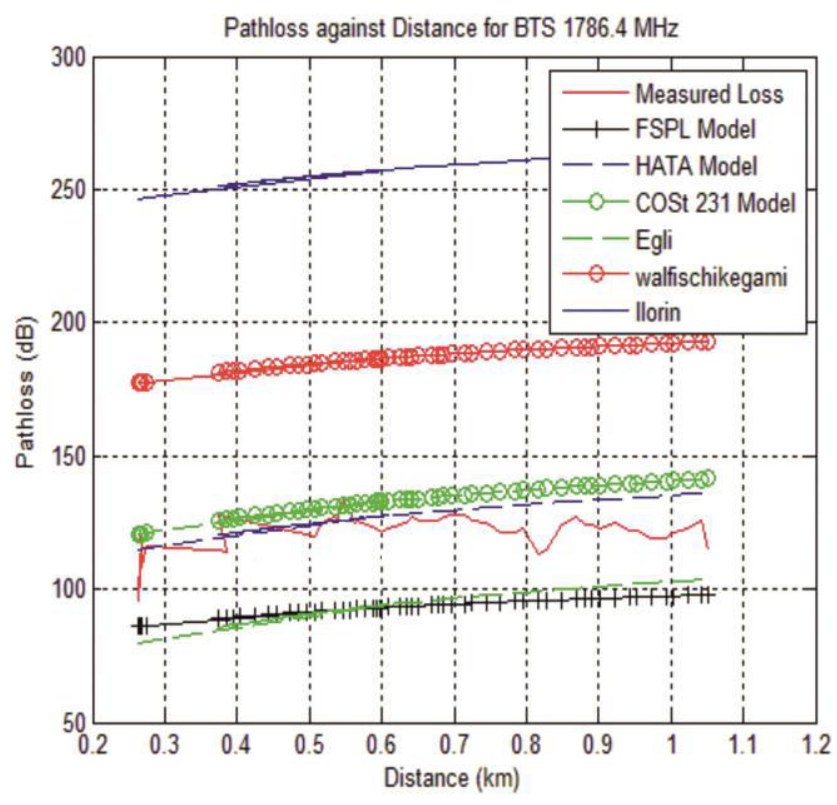

Fig 4.3. Comparison of empirical

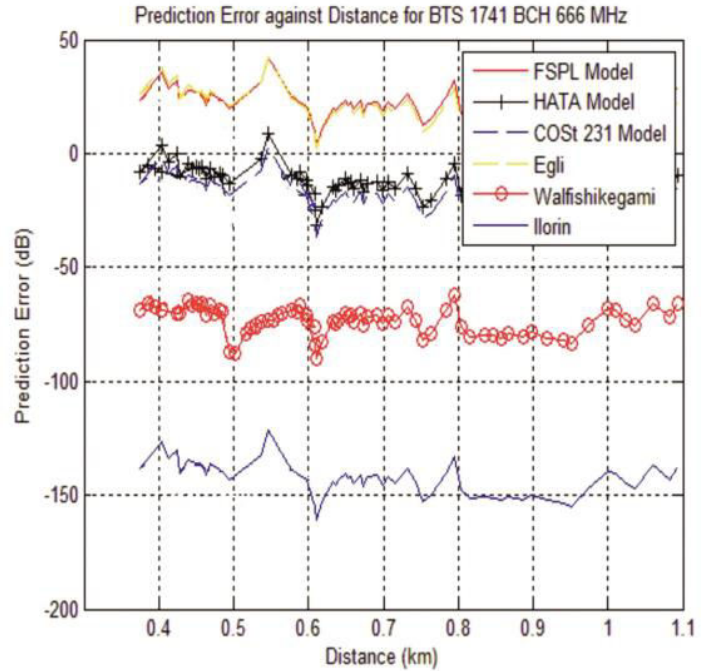

models with measured path loss along Hotoro Figure 4.4 prediction Error against distance for the Basic empirical models along Hotoro route 
The graphical outcome of BCH666 is shown in Figures 4.3 and 4.4 above. It shows the path loss caused by the empiric model. Of all the calculation routes tested, the Hata and COST 231 models are marginally more cautious within the first few kilometres, but later performed painfully. Followed by Egli model while ILORIN and Walfishikegami over predicted, throughout the route of studies while free space loss under predict the path loss throughout the route.

Figure 4.4 represent the predicted error against Distance for BCCH 666 the Graph is used to know the degree of prediction Error, and the closer the value to Zero the better it is i.e the accurate it is, While the Farer away from zero the more error the model has in that particular route and from the above graph it is shown that Hata model and Cost 231 are closer to zero, which mean they have lesser Error followed by Egli, walfish Ikegami while Ilorin has highest degree of Error, since is farer away from zero and this is because the model was built for radio and television channels.

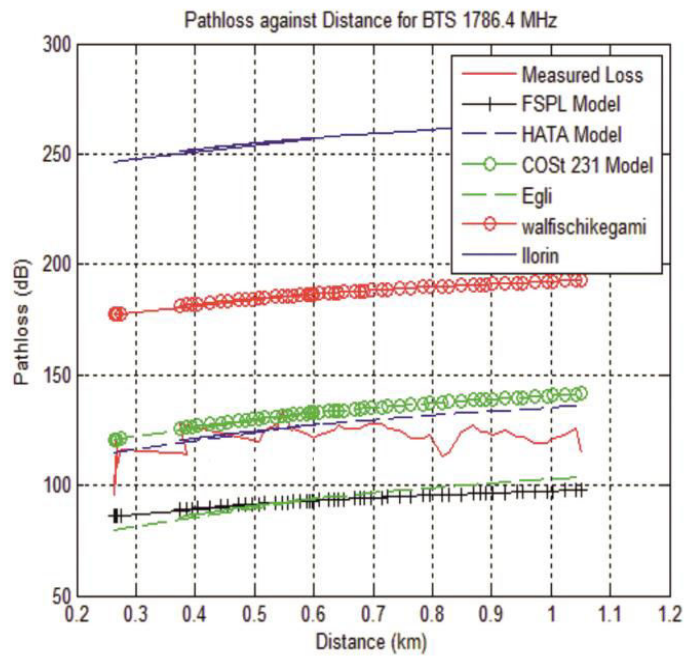

Fig 4.5. Comparison of empirical models with measured path loss Hotoro-Kaduna-Zaria highway along the eastern bypass road.

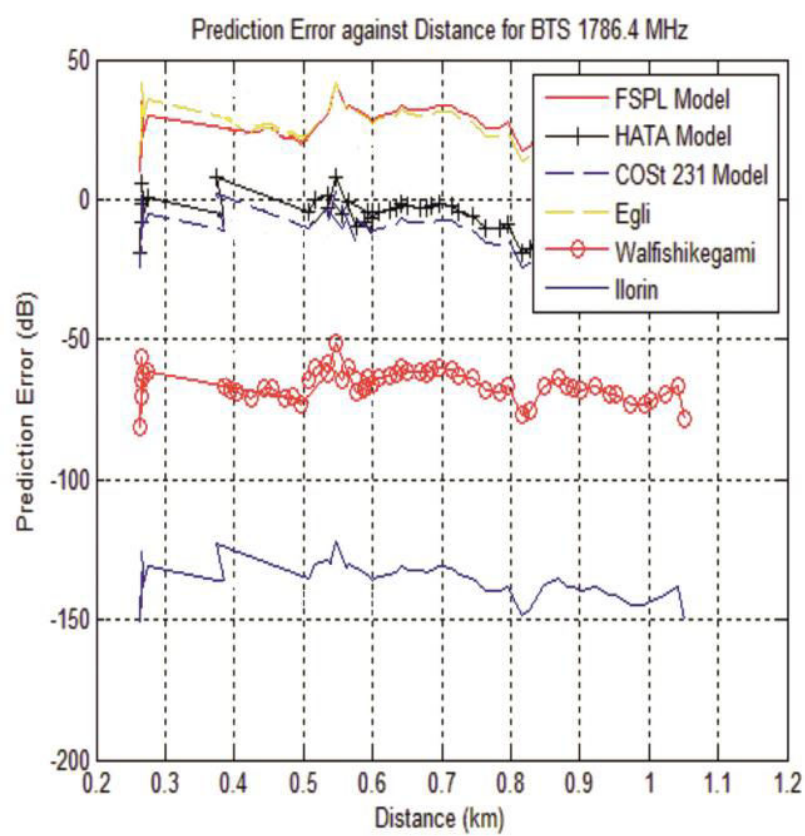

Figure 4.6 prediction Error against distance for the Basic empirical models along Hotoro-KadunaZaria highway along the eastern bypass road.

In Figures $4.54 .6,4.7,4.8$ and 4.9 , it is worth noting that the Hata and Cost 231 prediction models display symmetry for a few kilometers with a small discrepancy between 1.5 $\mathrm{km}$ and $2.5 \mathrm{~km}$ on some routes and show a lack of symmetry on some routes after which the cost 231 model over predicts a minor loss of pathways.

The Hata model gives the best result along this path, as it has low forecast Error graphically and via performance metrics. This suggests that, for the broader range loss prediction, the Hata model would do better than the commonly used cost 231 model

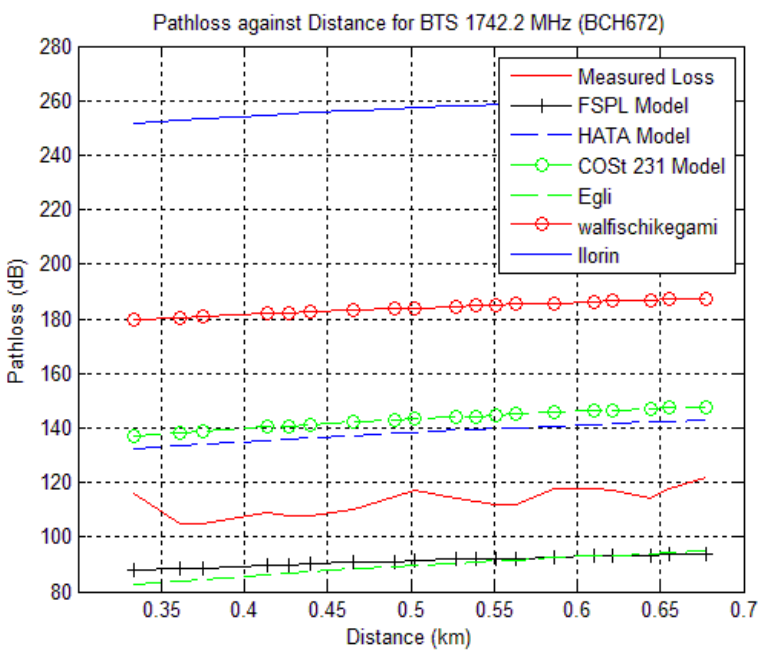

Figure 4.7 Comparison of empirical models with measured path loss along Dan Agundi route 


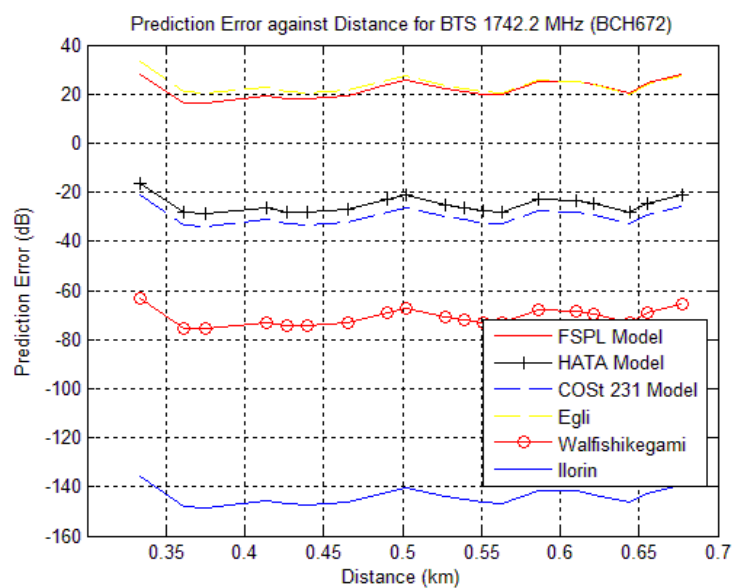

Figure 4.8 prediction Error against distance for the Basic empirical models along Dan Agundi route

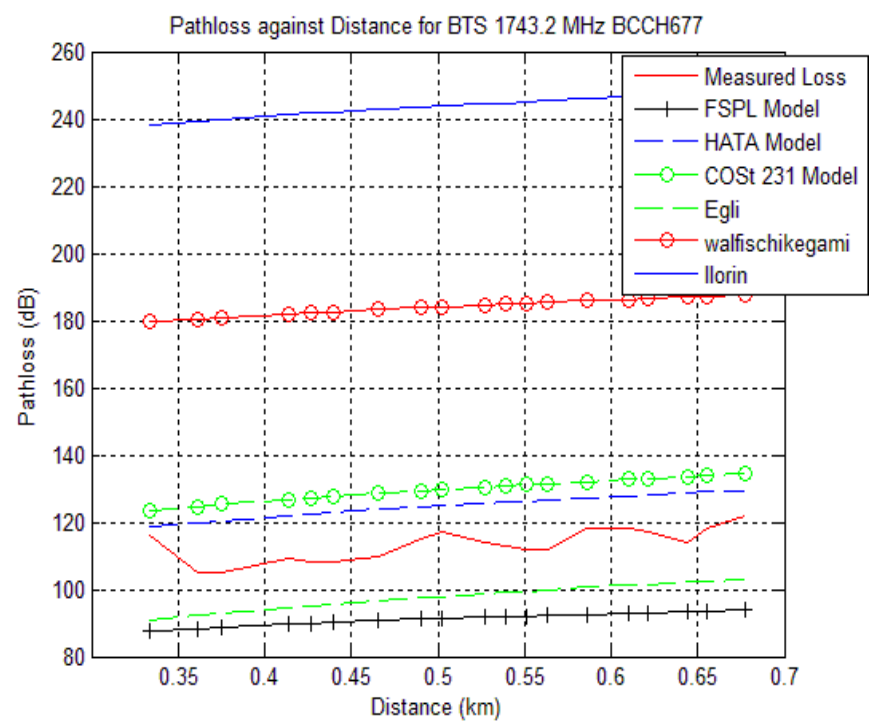

Fig 4.9.Comparison of empirical models with measured path loss along Gwarzo Road.

The above results show that no single model reliably produces a good match. The health test is when the RMSE value in the urban scenario is between $0-10 \mathrm{~dB}$ and in the rural scenario is between 10-15 $\mathrm{dB}[6]$ (Abhayawardhana, 2005). Hata and Cost 231 models, however, provide reasonable fitness along some selected measured routes with calculated RMSE values below 15 dB. The models Walfisch, Ikegami, Egli, ILORIN and FSPL perform worst, with higher RMSE. Further tests on the error spread as a function of distance along a wider route showed that the Cost231 model provides a better fit over Hata, which is possibly expected since the Hata model is only true for a maximum transmission distance of $20 \mathrm{~km}$.[6] (Abhayawardhana,2005). The related RMSE and
STDV error figures are shown in Tables 4.1 and 4.2.

Table 4.1 Estimation Error for the BTS calculated

\begin{tabular}{|c|c|c|c|c|c|c|}
\hline BTS & FSPL & $\begin{array}{l}\text { HAT } \\
\text { A }\end{array}$ & $\begin{array}{l}\text { COS } \\
\mathrm{T}\end{array}$ & EGLI & $\begin{array}{l}\text { WALFIS } \\
\mathrm{H}\end{array}$ & $\begin{array}{l}\text { ILORI } \\
\mathrm{N}\end{array}$ \\
\hline $\begin{array}{l}\text { BCCH66 } \\
8\end{array}$ & 27.218 & 7.224 & 12.31 & 16.38 & 18.836 & -136.8 \\
\hline $\begin{array}{l}\text { BCCH66 } \\
6\end{array}$ & $\begin{array}{l}20.507 \\
1\end{array}$ & $\begin{array}{l}13.95 \\
9\end{array}$ & $\begin{array}{l}19.31 \\
1\end{array}$ & 19.305 & -72.830 & $\begin{array}{l}143.40 \\
5\end{array}$ \\
\hline $\begin{array}{l}\text { BCCH66 } \\
2\end{array}$ & $\begin{array}{l}- \\
90.905\end{array}$ & 9.326 & $\begin{array}{l}14.67 \\
7\end{array}$ & $\begin{array}{l}- \\
24.303\end{array}$ & 68.77 & $\begin{array}{l}139.04 \\
3\end{array}$ \\
\hline $\begin{array}{l}\text { BCCH67 } \\
2\end{array}$ & 21.894 & $\begin{array}{l}25.24 \\
1\end{array}$ & $\begin{array}{l}30.07 \\
7\end{array}$ & 23.522 & -70.918 & $\begin{array}{l}- \\
144.09 \\
8\end{array}$ \\
\hline $\begin{array}{l}\text { BCCH67 } \\
7\end{array}$ & 33.846 & $\begin{array}{l}5.616 \\
2\end{array}$ & $\begin{array}{l}11.22 \\
1\end{array}$ & $\begin{array}{l}31.710 \\
3\end{array}$ & -57.629 & $\begin{array}{l}116.30 \\
6\end{array}$ \\
\hline $\begin{array}{l}\text { BCCH77 } \\
2\end{array}$ & 24.556 & 8.756 & 15.77 & 32.606 & -76.424 & $\begin{array}{c}120.09 \\
8\end{array}$ \\
\hline
\end{tabular}

Table 4.2Root mean square for the measured BTS

\begin{tabular}{|l|l|l|l|l|l|l|}
\hline BTS & FSPL & HATA & COST & EGI & WALFI & ILORI \\
8 & & & & & $\mathrm{~S}$ & $\mathrm{~N}$ \\
\hline BCCH66 & 27.753 & 12.299 & 13.691 & 37.82 & 13.639 & 136.891 \\
6 & & 7 & & & & 9 \\
\hline BCCH66 & 21.559 & 12.720 & 20.620 & 18.04 & 73.149 & 142.689 \\
\hline BCCH66 & 91.278 & 12.233 & 23.191 & 31.32 & 70.298 & 139.984 \\
\hline BCCH67 & 22.186 & 12.450 & 30.253 & 23.74 & 70.99 & 144.131 \\
2 & 2 & 9 & & 8 & & \\
\hline BCCH67 & 35.796 & 12.826 & 14.430 & 35.20 & 59.010 & 117.080 \\
7 & & 5 & & 4 & & \\
\hline BCCH77 & 25.907 & 11.865 & 20.445 & 38.34 & 60.046 & 145.537 \\
2 & & & & 5 & & \\
\hline
\end{tabular}




\section{RESEARCH OUTCOMES AND FUTURE ENHANCEMENT}

The performance of five empirical path loss models, which are often used in estimating signal path losses, was studied using statistical methods such as mean error, relative mean error, and percentage ranking along five routes in Kano State, Nigeria.

The performance criteria were based on percentage performance in prediction, with models having prediction performance values between the range of $70 \%$ to $80 \%$ as the best fit models[7][8],

However, the findings shows that the Hata and Cost 231 models consistently offer better prediction in all five measurement approaches. Hata and Cost231 models, on average, provide better fit outcomes, whereas Egli and walfish ikegami models provide the poorest performance results[9].

It was found that HATA model provides the best results in terms of minimum mean Error, RMSE and SCRMSE. HATA model has the best fit which falls within the acceptable range of $\pm 10 \mathrm{~dB}$.

As a result, error analysis is required to evaluate the amount of variation from the defined model and its actual execution outside of the regions for which it was designed. As a result, precise assessment of propagation models in the GSM and WCMDA bands is required in order to change/modified a model or pick a model that provides better fits in order to achieve high accuracy in the planning, design, and even implementation stages[10][11].

\section{CONCLUSION}

The recorded path loss was compared to the anticipated path loss using the HATA, COST 231, Walfisch Ikegami, Egli, and Iorin models. For GSM band, HATA model provides least mean error and RMSE of $5.9 \mathrm{~dB}$ and 11.86 $\mathrm{dB}$ respectively. However, for WCDMA band, Hata and COST 231 models give RMSE values of $16.6 \mathrm{~dB}$ and 14.7 $\mathrm{dB}$ respectively. The COST 231 model performs well in the WCDMA band, which is to be expected given that its frequency validity extends up to $2 \mathrm{GHz}$, while Hata is restricted to $1500 \mathrm{MHz}$. However, in urban areas, RMSE values of up to $15 \mathrm{~dB}$ are acceptable, while in suburban and rural areas, RMSE values of up to $10 \mathrm{~dB}$ are acceptable. To achieve optimal coverage prediction, Hata or COST 231 models must be modified to reduce RMSE values within an acceptable range.

\section{ACKNOWLEDGEMENTS}

An acknowledgement section may be presented after the conclusion, if desired.

\section{REFERENCES}

[1] Parson, J. D., (1992) Mobile Radio Propagation Channel, Wiley, Chichester, West Sussex, England,.

[2] Adetiba, E., Iweanya, V. C., Popoola, S. I., Adetiba, J. N., \& Menon, C. (2017).
Automated detection of heart defects in athletes based on electrocardiography and artificial neural network. Cogent Engineering, 4(1), 1411220.

[3] Anderson, E., Phillips, C., Sicker, D. \& Grunwald, D. (2008) "Modeling environmental

effects on directionality in wireless networks," in Proceedings of the 5th International Workshop on Wireless Network Measurements (WiNMee),

[4] Faruk, N., A. Ayeni, amd Y. A. Adediran, (2013).“On the study of empirical pathloss models for accurate prediction of Tv signal for secondary users," Progress In Electromagnetics Research B, Vol. 49,155-176,.

[5] E. Greenberg, E. Klodzh (2005), "Comparison of deterministic, empirical and physical propagation models in urban environments", Microwaves, Communications, Antennas and Electronic Systems (COMCAS), IEEE 2005. PIMRC 2005. IEEE 16th Int. Symp. on, vol. 1, no., pp. 659-663, 11-14 Sept. 2005.

[6] Abhayawardhana, V.S., Wassell, I.J., Crosbsy, D., Sellars, M.P. and Brown, M.G. (2005) 'Comparison of empirical propagation path loss models for fixed wireless access systems', IEEE Vehicular Technology Conference, Vol. 1, pp.73-77.

[7] Adetiba, E., \& Olugbara, O. O. (2015). Lung cancer prediction using neural network with histogram of oriented gradient genomic features. The Scientific World Journal, 2015.

[8] Faruk, N.; Adediran, Y. A.; Ayeni A. A. and Surajudeen Ba-kinde, N.T. (2014). Improved path-loss model for predicting TV coverage for secondary access. International journal of mobile and wireless computing, Vol 7. pp.565-576.

[9] Abuonji Paul (2021), Discovery and Diminution of Variance between Actual and Expected Outsourced Bandwidth Supply in Corporate Network Infrastructure, Int. J. Advanced Networking and Applications Volume: 13 Issue: 01 Pages: 4833-4838(2021) ISSN: 0975-0290

[10] Kayalvizhi, E. \& Gopalakrishnan, B., (2021), Adaptive Resource Optimization for Cognitive Radio Networks; Int. J. Advanced Networking and Applications Volume: 12 Issue: 06 Pages: 4793-4799(2021) ISSN: 0975-0290

[11] Tanenbaum, A. S. (2011). Computer Networks; 4 th ed. Prentice-Hall, Inc: New Jersey.

[12] Vaneeta\& Rani, S. (2021). A Perspective for Intrusion Detection \&Prevention in Cloud 
Environment; Int. J. Advanced Networking and Applications, Volume: 12 Issue: 06 Pages: 47704775(2021) ISSN: 0975-0290

[13] Cocca, P. (2004). SANS Institute InfoSec Reading Room: Email Security Threats. Retrieved on 17th November, 2012 from: http://www.sans.org/reading_room/whitepapers/e mail/email-security-threats_1540

[14] Hamdy H. Elsayed,Hassan ShabanHassan , 'Performance Comparison of Various HierarchicalWSN Routing Protocols', Int. J. Advanced Networking and Applications,Volume: 11 Issue: 02 pp. 4218-4223, ISSN: 0975-0290, 2019.

[15] Hamdy H. Elsayed, 'Effects of Number of Nodes and Network AreaSize Parameters on WSN Protocols Performances', Int. J. Advanced Networking and Applications,Volume: 11 Issue: 02 pp. 4244 4251, ISSN: 0975-0290,201

\section{Biographies and Photographs}

Mr. Saheed Tunde Zubair, is currently working as a Lecturer in Department of Computer Science, School of Science and Technology, Skyline University Nigeria, Kano, Nigeria. He has completed his post graduate higher studies under Bayero University, Nigeria. He has more than 8 years of experience in teaching field. He has extended his service in collaborative research projects and valuable supervision, guidance in under graduate Engineering projects. He has taught different courses such as Operating systems, Computer Organization \& Architecture, E-commerce, Data structures etc. $\mathrm{He}$ is actively participating in lecturing and research publication works. He is also interested in research areas of big data, cyber security, Telecommunications etc.

Dr. Vijay Arputharaj J is a Doctorate in Computer Science and HOD - Computer Science, Skyline University Nigeria; He has also completed an integrated Post Graduate, Masters Degree in Software Systems 20052010, Bharathiar University. A professional with more than 11 years of progressive experience in lecturing. Currently he is having working experience in India, Ethiopia and Nigeria. He has also served as Head of Software Engineering Department, Jijiga University, Ethiopia. He has carried out additional responsibilities as Exam Cell Convener, 2012-2014 at VLB Janakiammal College, India by conducting centralized internal exams. $\mathrm{He}$ has also undertaken number of training and development programs such as "Enhancing Teaching Skills" conducted by Wipro. Followed by training on "Academic Performance Indicators" at Bharathiar University, India. He is also a part of Educate Community Programme - CSR Activity carried by Skyline University Nigeria. He also served for number of physically challenged and disabled students by training them and designed a certificate diploma programme for them in computer science and applications.
Dr.Ashok Kumar has vast experience in teaching and research in different Institutions of Higher Learning. He has done his research work in Sri Nandhanam College of Engineering and Technology, Tamilnadu, India. He has also worked as Data Scientist / Intern in Data Foundry Pvt Ltd, Bangalore, India. His research interests are in the area of Data mining, Machine Learning and Artificial Intelligence. He has 7 research papers in national and international Journal publications to his credit.

Ms. Pushpa Rega Ganesan, is currently working as a Lecturer in Department of Software Engineering, Institute of Technology, Jigjiga University, Ethiopia. She has completed her higher studies under Anna University, India. She has more than 5 years of experience in teaching field. She has extended her service in collaborative research projects and valuable supervision, guidance in under graduate engineering projects. She has taught different courses such as operating systems, human computer interaction, microprocessor, compiler design etc. She is actively participating in lecturing and research publication works. She is also interested in research areas of big data, gene mining, gene sequence data analysis etc. 